\title{
Biogeography Based Optimization Tuned Fuzzy Logic Controller to Adjust Speed of Electric Vehicle
}

\author{
Salam Waley ${ }^{*^{1}}$, Chengxiong Mao $^{2}$, Nasseer K. Bachache ${ }^{3}$ \\ ${ }^{1,2}$ State Key Laboratory of Advanced Electromagnetic Engineering and Technology, \\ Wuhan, China \\ ${ }^{3}$ School of Electrical \& Electronic Engineering, Huazhong University of Science and Technology, \\ Wuhan, China \\ ${ }^{3}$ College Univesity of Humanity Studies, Najaf, Iraq \\ ${ }^{*}$ Corresponding author, e-mail: salam waley73@yahoo.com¹, cxmao@hust.edu.cn ${ }^{2}$, \\ tech_n2008@yahoo.com ${ }^{3}$
}

\begin{abstract}
There are many power electronic converters and motor drives connected together to form the electrical system of an Electric Vehicle. In this paper, we have presented a modeling tool that has the advantages of utilizing capabilities of the PMSM software in detailed simulations of converters, motor drives, and electric machines. In addition, equivalent electrical models of Electric Vehicle drive system. This paper also gives a brief idea of PMSM validity as an Electric Vehicle simulation tool. PMSM drive system is described and analyzed due to its importance in many applications especially in Electric Vehicle applications. This application is high efficiency, low inertia and high torque to volume ratio. In this paper we embody the simulation of Fuzzy Logic Controller. The controller govern the speed control of Electrical Vehicle EV using permanent magnet synchronous motor PMSM. This work characterizes to obtain the optimal parameters of FLC. Biogeography Based Optimization (BBO) is a new intelligent technique for optimization; it can be used to tune the parameters in different fields. The main contribution of this work efforts the ability of $B B O$ to design the parameters of FLC by determining the shapes of triangle memberships of the inputs and output. The results of optimal controller (BBO-FLC) compared with the other controllers designed by Genetic Algorithm GA which it is a powerful method has been found to solve the optimization problem. The implementation of BBO algorithm has been done by M-file/Matlab, this program linked with SIMULINK to calculate the finesses function which has the complete mathematical system model has implemented using. The results show the excellent performance of BBO-FLC compared with GA-FLC and PI controller, also the proposed method was very fast and need a few number of iterations. These results also confirmed that the transient torque and current never exceed the maximum permissible value.
\end{abstract}

Keywords: biogeography-based optimization (BBO), fuzzy logic controller (FLC), electrical vehicle (EV), permanent magnet synchronous motor (PMSM)

Copyright ( 2015 Institute of Advanced Engineering and Science. All rights reserved.

\section{Introduction}

We think the concern about the environment and energy security such as increasing gasoline prices or depletion of fossil fuels is changing, due to emerged electric vehicles are used, another word the passenger vehicles will be enabled on the grid, many researchers have recognized that electric drive vehicles are critical to the future of the industry [1]. However, some challenges exist to greater adoption, in United States has pledged to reduce greenhouse gas (GHG) emissions by approximately 17 percent before the year 2020 then forecast 7 million EV will be sold, the perception of EV cost also charging infrastructure may developed, we believe that numerous advantages for Electric Vehicles EVs compared with Internal Combustion Engine ICE vehicles, especially the EVs have a high energy efficiency, while the energy efficiency of ICE vehicles is about $30 \%$, the energy efficiency of EVs is over than $80 \%$, [2]. PMSM became at the top of ac motors in the medium range of power and it became very popular choice in drive technology over the last few years due to some of its inherent advantages. These advantages include high torque to current ratio, large power to weight ratio, higher efficiency and robustness. There are many application of PMSM in Elevators, Wind Energy, EV drive and etc. because it allows an enlarged speed range with inverter size lower than in a conventional flux- 
oriented induction motor drive $[3,4]$. In [5], the adaptive dynamic surface control (DSC) of PMSM has been presented. In [6, 7], the authors had derived some feedback control design methods for stability of PMSM in their results. Some control methods had studied to stabilize the PMSM systems, such as sliding mode control (SMC)[8],differential geometry method [9], passivity control [10, 11]. The tangible benefit of choosing controller is its simplicity to implement. It is not easy to find another controller with such a simple structure to be comparable in performance. Fuzzy rule-based models are easy to comprehend because it uses linguistic terms and the structure of if-then rules [12,13]. A very important step in the use of controllers is the controller parameters and tuning process [14]. Unfortunately, in spite of this large range of tuning techniques, the optimum performance cannot be achieved. In recent year there are many intelligent optimization techniques have been emerged and get a great attention of researchers like Genetic Algorithm (GA), Particle Swarm Optimization (PSO) techniques bee colony optimization (BCO), Ant Colony Optimization (ACO), Simulated Annealing (SA), and Bacterial Foraging (BF) [15]. Usually GA has a most algorithms founded in the control field, like the search for optimal parameters of FLC controller. But it still requires enormous computational effort. In this paper we suggest a new computational theory named (Biogeography-Based Optimization BBO) to tuneparameters of FLC controller. This controller can govern a non-linear system.

\section{Model for a PMSM Drive}

The complete nonlinear model of a PMSM without damper windings is as follows:

$$
\begin{aligned}
& \mathrm{v}_{\mathrm{q}}=\mathrm{Ri}_{\mathrm{q}}+\mathrm{pL}_{\mathrm{q}} \mathrm{i}_{\mathrm{q}}+\omega_{\mathrm{s}}\left(\mathrm{L}_{\mathrm{d}} \mathrm{i}_{\mathrm{d}}+\lambda_{\mathrm{af}}\right) \\
& \mathrm{v}_{\mathrm{d}}=\mathrm{Ri}_{\mathrm{d}}+\mathrm{p} \lambda_{\mathrm{d}}-\omega_{\mathrm{s}} \mathrm{L}_{\mathrm{q}} \mathrm{i}_{\mathrm{q}}
\end{aligned}
$$

$v_{d}$ and $v_{q}$ are the $d, q$ axis voltages, id and iq are the $d, q$ axis stater currents, Ld and Lq are the $\mathrm{d}, \mathrm{q}$ axis inductance, $\mathrm{R}$ and $\omega_{s}$ are the stater resistance and inverter frequency respectively. $\lambda_{a f}$ is the flux linkage due to the rotor magnets linking the stator.

The electric torque:

$$
\mathrm{T}_{\mathrm{e}}=3 \mathrm{P}\left(\lambda_{\mathrm{af}} \mathrm{i}_{\mathrm{q}}+\left(\mathrm{L}_{\mathrm{d}}-\mathrm{L}_{\mathrm{q}}\right) \mathrm{i}_{\mathrm{d}} \mathrm{i}_{\mathrm{q}}\right) / 2
$$

The motor dynamics:

$$
\mathrm{T}_{\mathrm{e}}-\mathrm{T}_{\mathrm{L}}+B \omega_{r}+J p \omega_{r}
$$

$P$ is the number of pole pairs, TL is the load torque, $B$ is the damping coefficient, $\omega_{r}$ is the rotor speed and $\mathrm{J}$ the moment of inertia. The inverter frequency is related to the rotor speed as follows:

$$
\omega_{s}=p \omega_{r}
$$

The machine model is nonlinear as it contains product terms such as speed with id and iq. Note that $\omega_{r}, i_{d}$ and $i_{q}$ are state variables. During vector control, $i_{d}$ is normally forced to be zero.

$$
\mathrm{T}_{\mathrm{e}}=3 \mathrm{P} \lambda_{a f} \mathrm{i}_{\mathrm{q}} / 2=\mathrm{K}_{\mathrm{t}} \mathrm{i}_{\mathrm{q}}
$$




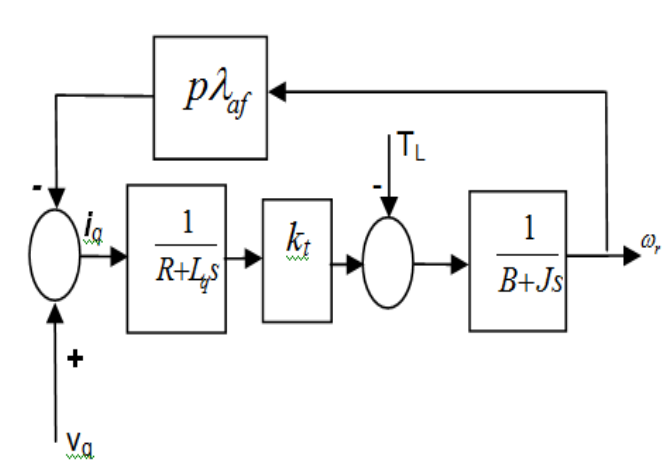

Figure 1. Block diagram of a PMSM

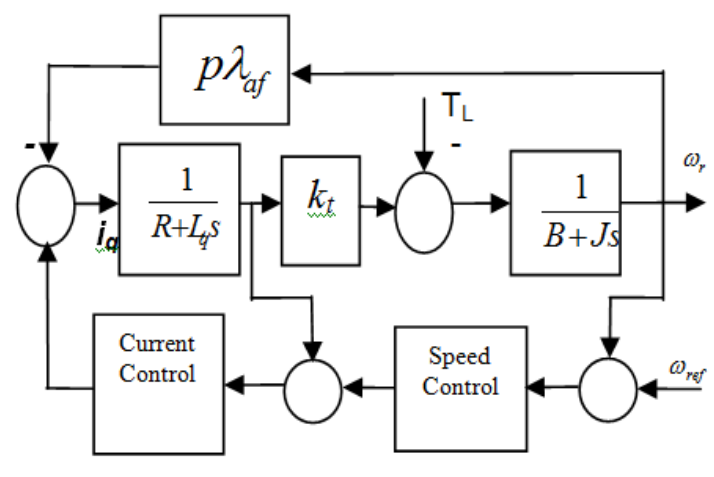

Figure 2. Block diagram of a PMSM Drive

\section{Speed Control of PMSM Motor}

The PMSM is using control to suppress harmonic noise to a level then, noise to a level below and vibration translates into a more comfortable ride for passengers. IGBT SPWM inverters make the ride more smoother with precisely adjusting speed control with frequency and voltage regulation.It has the latest low-noise power units to make the ride even quieter. Elevator has directed high-speed used (1500 rpm) PMSM. Energy reform in the elevator geared for small rise because travel extremely small and fast.

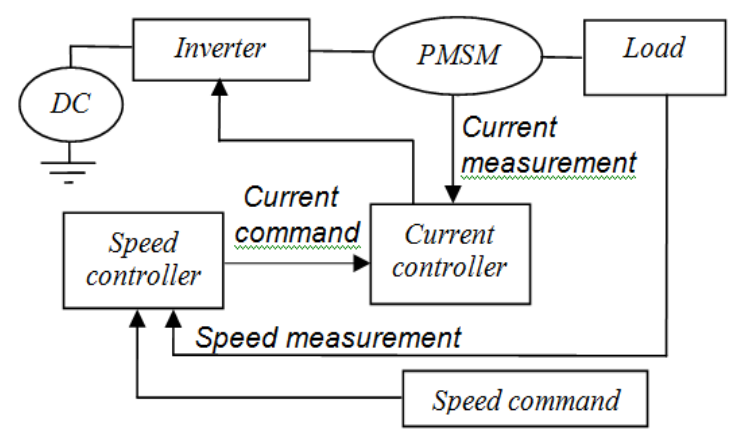

Figure 3. Block Diagram of Speed Control of PMSM

\subsection{Biogeography-Based Optimization}

Inspired of biogeography Simon developed a new approach called Biogeography-Based Optimization (BBO) in (2008). This algorithm is an example of how a natural process can be modeled to solve optimization [18]. In n BBO, each possible solution is an island and their features that describe habitability are named Habitat Suitability Index (HSI). The goodness of each solution is named Suitability Index Variables (SIV). For example of the natural process, why some islands may lean towards to accumulate many more species than others? Because of possess certain environmental features that are more suitable to sustaining that kind than other islands with fewer species. It is axiomatic the habitats with high HSI have large populations, also high immigration rate and by feature of a large number of species that migrate to other habitats. The rate of immigration will be lower if these habitats are already saturated with species. On the other hand, habitats with low HSI have high immigration and low immigration rate, because of the sparse population.

The fitness function FF is associated with each solution of Biogeography-Based Optimization BBO, which is analogous to $\mathrm{HSI}$ of a habitat. A good solution is analogous to a habitat having high $\mathrm{HSI}$ and a poor solution represents a habitat having a low HSI. The best solutions share their geographies of the lowest solutions throw migration (emigration and immigration). Best solutions have more resistance to change than lowest solutions. While the lowest solutions have more change from time to time and accept many new features from best 
solutions. The immigration rate and emigration rate of the jth island may be formulated as follows in Equation (7), (8) [17].

$$
\begin{aligned}
& \lambda_{i}=I\left(1-\frac{j}{n}\right) \\
& \mu_{i}=\frac{E \cdot j}{n}
\end{aligned}
$$

Where $\mu, \lambda j$ are the immigration rate and the emigration rate of $j$ individual; $I$ is the maximum possible immigration rate; $E$ is the maximum possible emigration rate; $j$ is the number of species of $\mathrm{jth}$ individual; and $\mathrm{n}$ is the maximum number of species. best solutions.

Jth In BBO, the mutation is used to increase the diversity of the population to get the

Mutation operator modifies a habitat's SIV randomly based on mutation rate. The mutation rate $\mathrm{mj}$ is expressed in (9).

$$
m_{j}=m_{\max }\left(\frac{1-p_{j}}{p_{\max }}\right)
$$

Where $\mathrm{mj}$ is the mutation rate for the jth habitat having a $\mathrm{j}$ number of species; mmax is the maximum mutation rate; Pmax is the maximum species count probability; $\mathrm{Pj}$ the species count probability for the jth habitat and is given by Equation (10):

$$
P=\left\{\begin{array}{l}
-\left(\lambda_{j}+\mu_{j}\right) P_{j}+\mu_{j+1} P_{j_{+1}}, \quad j \leq 0 \\
-\left(\lambda_{j}+\mu_{j}\right) P_{j}+\lambda_{j_{-1}} P_{j_{-1}}+\mu_{j+1} P_{j_{+1}}, \quad 1 \leq j \leq n \\
-\left(\lambda_{j}+\mu_{j}\right) P_{j}+\lambda_{j_{-1}} P_{j_{-1}}, \quad j=n
\end{array}\right.
$$

Where $\mu j+1, \lambda j+1$ are the immigration and emigration rate for the jth habitat contains $j+1$ species; $\mu \mathrm{j}-1, \lambda \mathrm{j}-1$ are the immigration and emigration rate for the jth habitat contains $\mathrm{j}-1$ species.

\subsection{Fuzzy Logic Controller}

Fuzzy logic controllers have the following advantages over the conventional controllers that they are cheaper to develop, they cover a wide range of operating conditions, and they are more readily customizable in natural language terms. In Mamdani type FIS the crisp result is obtained by defuzzification [16], in the Mamdani FIS can be used for both multiple input and single output and multiple inputs multiple outputs system as shown in Figure 4.

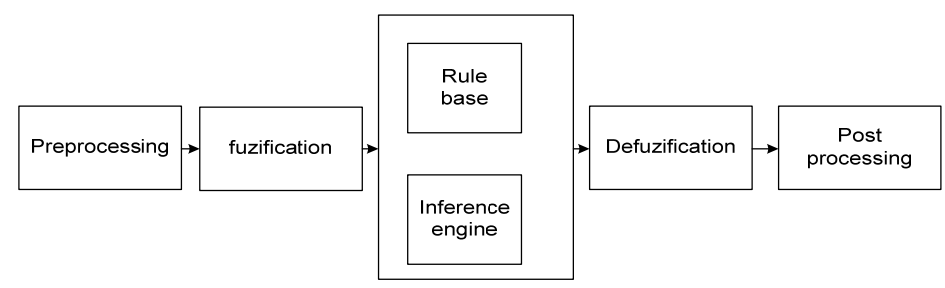

Figure 4. Arrangement of fuzzy logic controller

The usefulness of fuzzy logic controller is adopted especially in a complex and nonlinear system. The rules of conventional FLC are produced depend on the operator's 
experience or general knowledge of the system in a heuristic way. The thresholds of the fuzzy linguistic variables are usually chosen arbitrarily in the design process. An improper controller value leads to an adverse consequence, unstable mode, collapse and separation [11]. This work propose BBO to design an Optimal Fuzzy Logic Controller OFLC, the optimized criteria is how to minimizing the transient state.

\subsection{Genetic Algorithm Optimization}

Many optimization problems have come to be solved using Artificial Intelligent (Al). Relatively Genetic Algorithm (GA) is the most widely used in these techniques, it is a powerful tool even recently there are many new approaches have proposed for optimum searching. The variables are represented as genes on a chromosome. GAs features a group of population on the response surface. Through Natural Selection NS and genetic operators, mutation and crossover, chromosomes with better fitness functions FF are found. NS sureties the recombination operator, the Genetic Algorithm combine genes from best two parent chromosomes to generate two children that at least one of them have a better fitness from his parents. Mutation allows new areas of the response surface to be explored.

\subsection{SVPWM Inverter Simulation}

The Voltage Source Space Vector Pulse Width Modulation (SPWM) is the most popular usage in A.C drives. So; its performance should be a Voltage Source Inverter (VSI) and have a stiff source at the input [6]. A practical (VSI) consists of power bridge devices with three outputs; each one consists of two power switches and two freewheeling diodes. The inverter is supplied from D.C. voltage source via LC filter. In SVPWM, the three output legs considered as three independent push-pull amplifiers as shown in Figure 5.

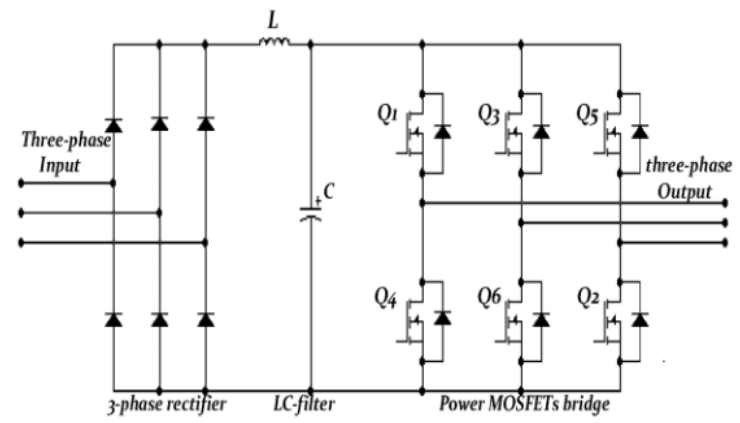

Figure 5. A three phase (VSI) with three phase rectifier

SVPWM inverter can be simulated by MATLAB/SIMULINK. The output of the switches gives (Vao,Vbo, $\mathrm{Vco}$ )then the three phases to load neutral $(\mathrm{Van}, \mathrm{Vbn}, \mathrm{Vcn})$ can be achieved by implementing Equation (11).

$$
\left[\begin{array}{l}
V_{a n} \\
V_{b n} \\
V_{c n}
\end{array}\right]=\frac{1}{2}\left[\begin{array}{ccr}
2 & -1 & -1 \\
-1 & 2 & -1 \\
-1 & -1 & 2
\end{array}\right]\left[\begin{array}{c}
V_{a o} \\
V_{b o} \\
V_{c o}
\end{array}\right]
$$

\subsection{Electric Vehicle (EV) System} inverter:

The diagram of an Electric Vehicle (EV) System using an PMSM supplied by voltage 


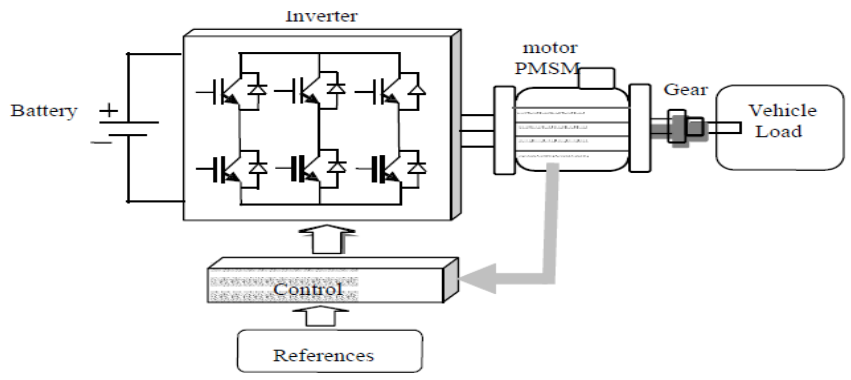

Figure 6. Electric Vehicle (EV) System

\subsubsection{The Vehicle Load}

The vehicle inertia torque defined by the following relationship:

$$
\operatorname{Tin}=J v\left(d w_{v} / d t\right)
$$

\subsubsection{Aerodynamics Force}

The force is due to the friction of the vehicle body, moving through the air.

$$
\text { Faero }=\left(\rho S T_{x} v^{2}\right) / 2
$$

The aerodynamics torque is:

$$
\text { Taero }=\left(\rho S T_{x} R_{r} v^{2}\right) / 2
$$

\subsubsection{Rolling Force}

The rolling resistance is primarily due to the traction of the tire on the rode. It is proportional to vehicle weight, the equation is:

$$
\begin{aligned}
& \text { Ftire }=M g f r \\
& \text { Ttire }=M g f r R w
\end{aligned}
$$

\subsubsection{Hill Climbing Force}

The force needed to drive the vehicle up a slope is the most straightforward to find.

$$
\text { Fslope }=M g \sin (\beta)
$$

The slope torque is:

$$
\text { Tslope }=M g \sin (\beta) R w
$$

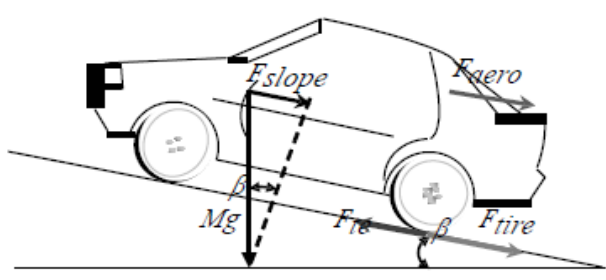

Figure 7. The vehicle up a slope 


\subsection{Elecric Vehicle Control System Application Flow Chart}

The Steps as follows (flow chart as Figure 8):

Step 1: Create the parameters of the Elecric Vehicle Drive system. system.

Step 2: According to the call signal and the current situation Elecric Vehicle Drive convergence.

Step 3: By Reload squadron by using update value-weighted inertial, with the speed of

Step 4: Use the acceptance criteria, to decide whether to accept these new particles or not, and to increase the diversity of the particles, with avoid trapping in local Optimization. loop (3).

Step 5: The end of the iteration, then the global search the optimal solution. If not, step

Step 6: by using Loop to step (2) until the end time simulation, then output the result.

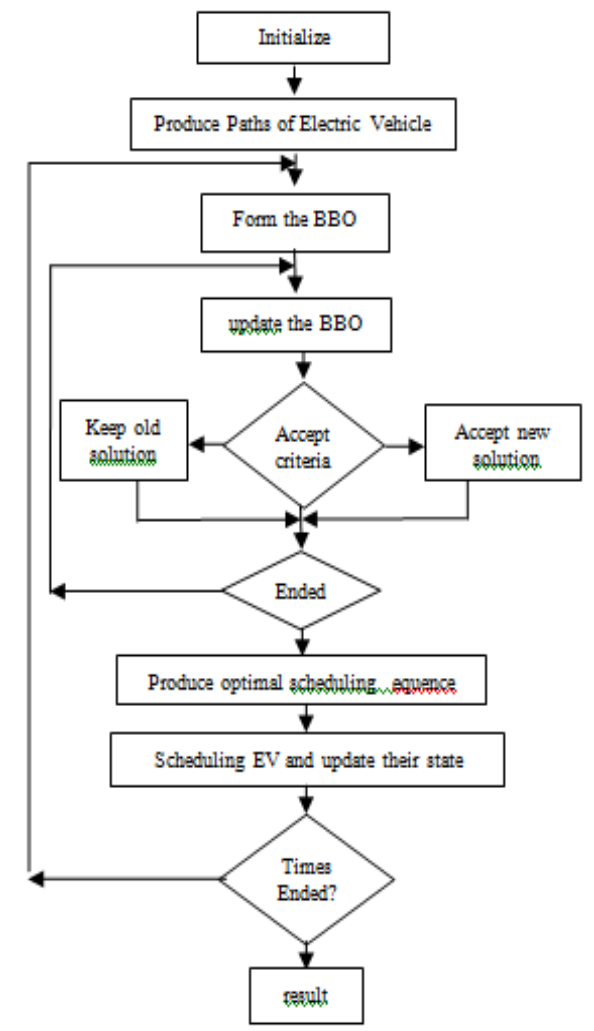

Figure 8. Electric Vehicle (EV) control system application flow chart

\section{Simulation Results}

By using Simulation model PMSM\&Simulation of EV Drive system by Implementing BBO Tuning for FLC Parameters.

\subsection{Implementing BBO Tuning for FLC Parameters}

The implementation of BBO in this work is same what complex, because the performance of the system must be examined in each iteration and particles position during the optimization algorithm. Therefore, the optimization algorithm is implemented by using MATLAB $\mathrm{m}$-file program and linked with the system simulation program in MATLAB SIMULING, to check the system performance in each iteration. In this paper, the problem summarized in optimizing three variables, they are: one output and two inputs (speed and the change in speed), each one has three dimensional spaces, represented as the prams of the triangle memberships of FLC. A random of 100 , Habitats were assumed and optimization algorithm of 100 iterations is used to 
estimate the optimal values of the FLC controller parameters. The fitness function FF which illustrated in Equation (19) can calculate by SIMULINK shown in Figure 9.

$$
F F=I T S E=\int_{0}^{t} t^{*} e^{2}(t) d t
$$

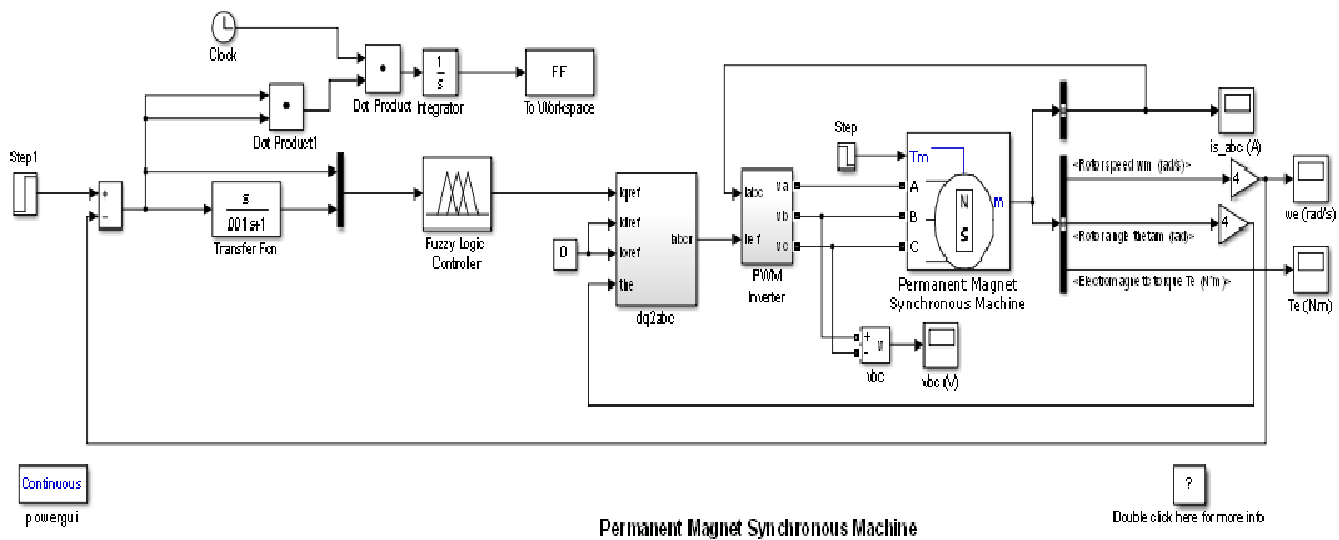

Figure 9. Model of the system

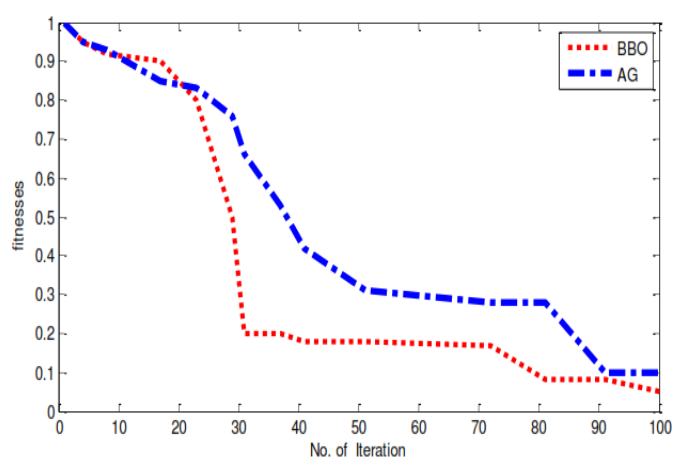

Figure 10. The convergence of Fitness Function in 100 Iterations

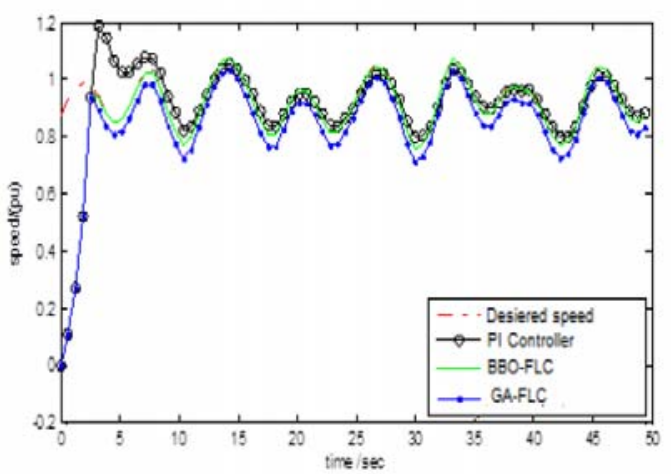

Figure 12. An arbitrary speed between (1.1pu and $0.7 \mathrm{pu}$ )

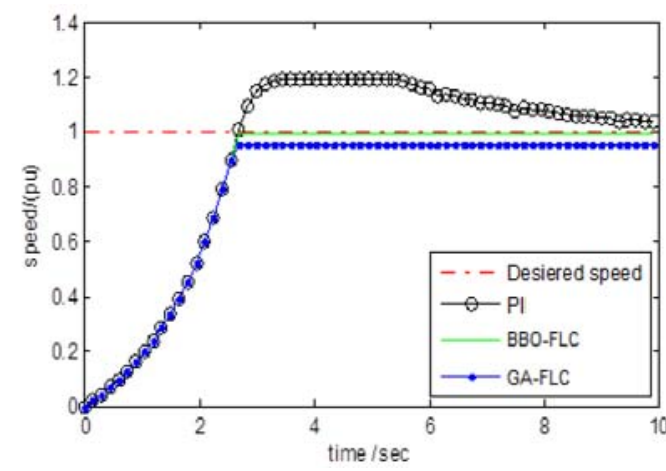

Figure 11. Step response OF PMSM speed in different controllers, GA-FLC and BBO-FLC and $\mathrm{PI}$ controller

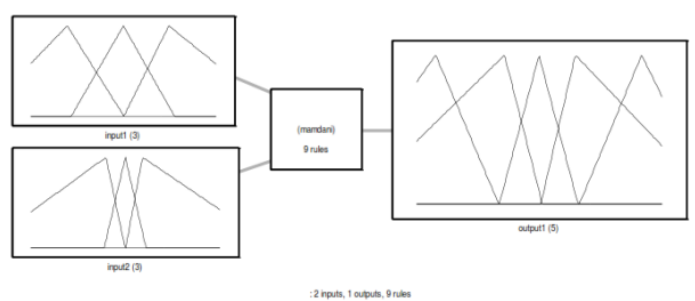

Figure 13. FLC memberships designed by BBO 
Figure 10 shows the convergence of Fitness Function in 100 iterations and the comparison between GA and BBO. Figure 11, 12 the step response with load and no load using proposed controller and GA-FLC and PI-controller tuned by conventional method trial and error. Figure 13 shows FLC designed by BBO and Figure 14 shows the surface of FLC

\subsection{Simulation of Elecric Vehcile Drive System}

Electric vehicle has submitted a number of tests during the various routes:

This test clarify the effect of the descent of vehicle moving on straight road, This test explain the effect of the slope on the EV, EV torque increase, the EV are driving in straight road with constant speed, the speed increase, the vehicle is driving on a curved road on the right side, the EV torque jumps down, the vehicle is driving on a curved road on the left side and EV torque jumps back.

\subsubsection{Speed, Torque \& Current Response with One Side at Speed $(500,600,400,500)$}

In this step there are three figures (a.speed response, b.Torque c.current), as show in figures below :

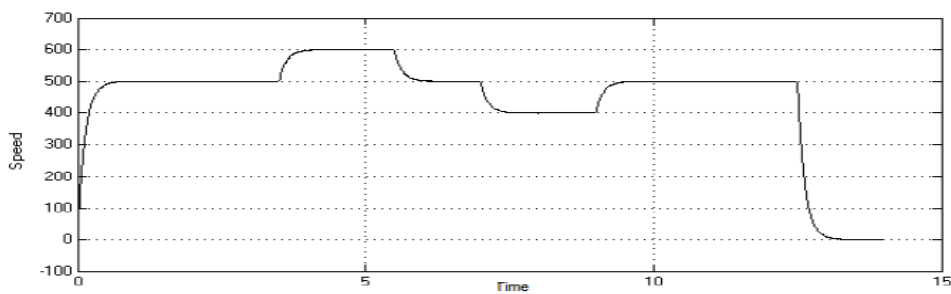

a) speed response

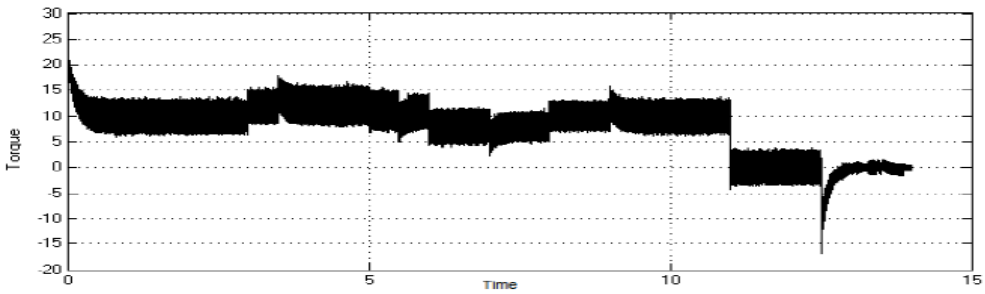

b) Torque response

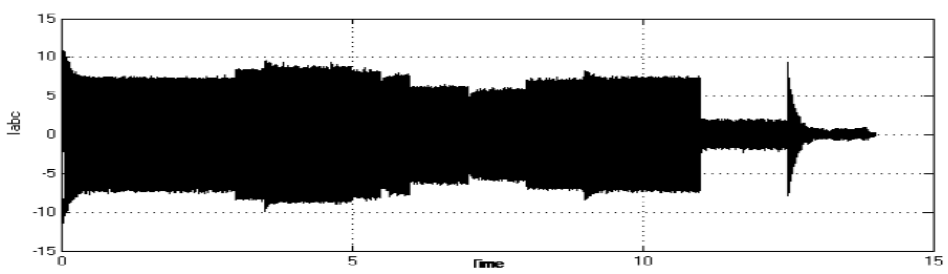

c) Current response

Figure 14. Simulation response of (a.speed, b.Torque c.current) with one side

4.2.2. Speed, Torque \& Current Response with Two Sides at Speed $(500,1000,1500,-500,-$ $1000,-1500)$

figures below:

In this step there are three figures (a.speed response, b.Torque, c.current), as show in 


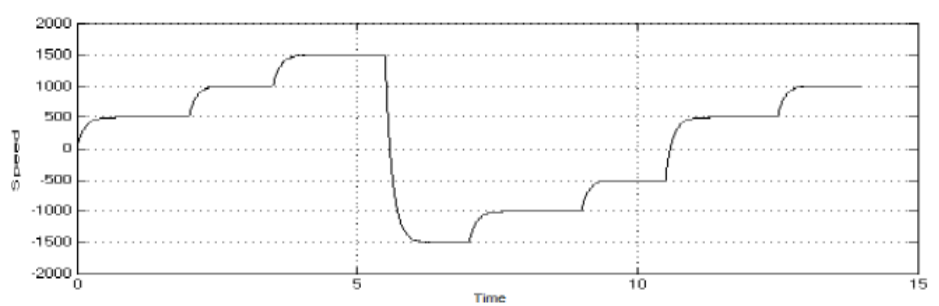

a) speed response

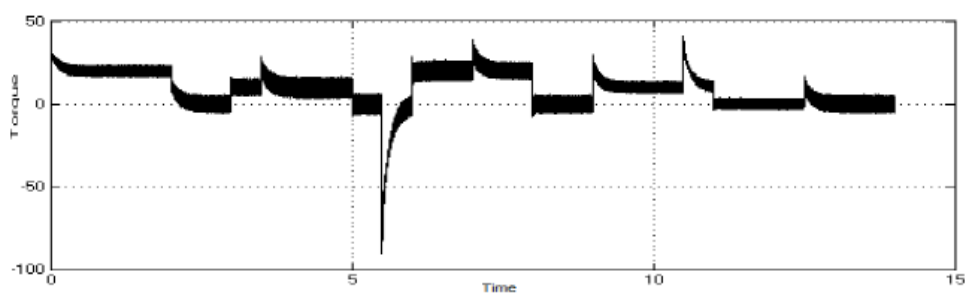

b) Torque response

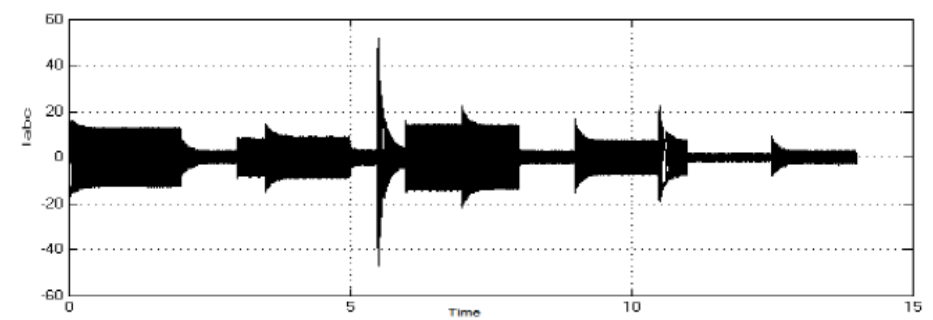

c) Current response

Figure 14. Simulation response of (a.speed, b.Torque, c.current) with two sides

\section{Conclusion}

The system responses of different tuning methods are illustrated in simulation result and a comparable performance between the three controllers in this research (PI controller, GAFLC and BBO-FLC) as shown in Figure 11, 12. We find the optimized BBO-FLC is closed with desired speed and its performance is the best compared with GA-FLC and PI controller.

We can obtain the following conclusions through simulation analysis:

1) This paper design fuzzy logic control by computational algorithm, it interject Control concepts of trial and error in fuzzy control and conventional GA-FLC method and then control velocity modulation of electrical vehicle $\mathrm{EV}$ in different speed.

2) Obviously, the BBO tuning of the FLC is the best intelligent method which gives an excellent system performance, and the GA gives a good response with respect to the traditional trial and error method.

3) In addition to the improving of system response, the BBO and GA can use a higher order system in the tuning process which avoids the error of system order reduction. It gave a satisfactory solution during the first 30 iterations as shown in Figure 11.

4) The proposed method makes control system have strong flexibility, instantaneity and reliability because of the advanced prediction of FLC predicting controller.

5) It makes control system have stronger Real-time controll ability because of optimal fuzzy parameters have ahead predict for a possible interfere source. The lower interference frequency, BBO algorithm is more controllable.

\section{References}

[1] Basu Malabika, Gaughan Kevin, Coyle Eugene. Harmonic distortion caused by EV battery chargers in the distribution systems network and its remedy. In 39th International Universities Power Engineering Conference, UPEC. 2004. 
[2] Hessamoddin J Moghaddam, Arash A Mardani, Seyed H Hosseinian. Influence of electric vehicle charging rates on transformer dating in harmonic-rich battery charger applications. Archives of Electrical Engineering. 2012; 61(4): 483-497.

[3] Dehkordi AB, Gole AA, Maguire TL. Permanent Magnet Synchronous Machine Model for Real -Time Simulation. Conference on Power System Transients (IPST'05). 2005.

[4] Salam Waley, Chengxiong Mao. Artificial Optimal Fuzzy Control Strategy for Elevator Drive System by Using Permanent Magnet Synchronous Motor. TELKOMNIKA Indonesian Journal of Electrical Engineering. 2015; 14(3): 470-480.

[5] DQ Wei, XS Luo, BH Wang, JQ Fang. Robust adaptive dynamic surface control of chaos in permanent magnet synchronous moto. Physics Letters, Section A. 2007; 363(1-2): 71-77.

[6] $Y$ Luo. Current rate feedback control of chaos in permanent magnet synchronous motor. In Proceeding of the CSU-EPSA. 2006; 18(6): 31-34.

[7] H Ren, D Liu. Nonlinear feedback control of chaos in permanent magnet synchronous motor. IEEE Transactions on Circuits and Systems II: Express Briefs. 2006; 53(1): 45-50.

[8] M Reichhartinger, M Horn. Sliding-mode control of a permenet-magnet synchronous motor with uncertainty estimation. International Journal of Mechanical and Materials Engineering. 2010; 1(2): 121-124.

[9] DQ Wei, XS Luo, JQ Fang, BH Wang. Controlling chaos in permanent magnet synchronous motor based on the differential geometry method. Acta Physica Sinica. 2006; 55(1): 54-59.

[10] DL Qi, JJ Wang, GZ Zhao. Passive control of permanent magnet synchronous motor chaotic systems. Journal of Zhejiang University. 2005; 6(7): 728-732.

[11] ZQ Wu, FX Tan. Passivity control of permanent-magnet synchronous motors chaotic system. Proceedings of the Chinese Society of Electrical Engineering. 2006; 26(18): 159-163.

[12] Hirulkar Sachin, et al. Design of Automatic Car Breaking System Using Fuzzy Logic and PID Controller. Electronic System, Signal Processing and Computing Technologies (ICESC), 2014 International Conference on. IEEE. 2014.

[13] Adnan Jabbar Attiya, Yang Wenyu, Salam Waley Shneen. Fuzzy-PID Controller of Robotic Grinding Force Servo System. TELKOMNIKA Indonesian Journal of Electrical Engineering. 2015; 15(1): 87-99.

[14] Castillo Oscar, Patricia Melin. A review on interval type-2 fuzzy logic applications in intelligent control. Information Sciences 279. 2014: 615-631.

[15] NK Bachache, JY Wen. PSO and GA designed Pareto of Fuzzy Controller in AC Motor, Drive. International Journal of Control and Automation. 2013; 6(6).

[16] Chen Cheng-Wu. RETRACTED: Applications of neural-network-based fuzzy logic control to a nonlinear time-delay chaotic system. Journal of Vibration and Control. 2014; 20(4): 589-605.

[17] Roy, Provas Kumar, Dharmadas Mandal. Optimal reactive power dispatch using quasioppositional biogeography-based optimization. International Journal of Energy Optimization and Engineering (IJEOE). 2012; 1(4): 38-55.

[18] Simon Dan. Biogeography-based optimization. Evolutionary Computation, IEEE Transactions. 2008; 12(6): $702-713$.

[19] Ma Haiping, Dan Simon. Blended biogeography-based optimization for constrained optimization. Engineering Applications of Artificial Intelligence. 2011; 24(3): 517-525. 